\title{
Political Marketing Elit Lokal Dalam Pemilihan Umum Kepala Daerah di Nusa Tenggara Barat
}

\author{
Fathurrijal \\ Program Studi Komunikasi Penyiaran Islam, Fakultas Agama Islam \\ Universitas Muhammadiyah Mataram,83115, Indonesia \\ fathur_mujaddid@yahoo.co.id
}

INFOARTIKEL

Riwayat Artikel:

DiterimaJuli 2018

Direvisi Agustus 2018

Disetujui September 2018
ABSTRAKSI

\begin{abstract}
Abstrak:Tulisan ini mengkaji penerapan komunikasi pemasaran politik (Political Marketing Communication) oleh Elit-elit Lokaldi beberapa momentum pemilihan umum kepala daerah di Nusa Tenggara Barat. Keberadaan elit lokal di NTB yang dulu hanya sebagai vote getter, kini telah menjelma menjadi tokoh politik yang siap berkompetisi dengan para politisi dalam merebut kepemimpinan formal di tingkat lokal. Kemampuan elit-elit lokal dalam menarasikan visi-misi politiknya tidak bisa dipandang sebelah mata oleh politisi-politisi murni yang selama ini menguasai struktural partai politik. Keterbukaan Demokrasi harus dijadikan sebagai media dan momentum untuk mendudukkan semua elemen masyarakat pemilih yang memiliki hak yang sama, sama-sama bisa diusulkan dan dipilih menjadi pemimpin-pemimpin birokrasi. Jalur politik adalah salah satu jalur yang memungkinkan elit lokal untuk bisa duduk mengisi pergantian kepemimpinan di level eksekutif dan legislatif. Provinsi NTB, sebagai salah satu daerah yang melaksanakan pemilihan umum kepala daerah sudah beberapa prioede kepemimpinan kini telah dipimpin oleh elit lokal yang berasal dari tokoh keagamaan, begitu juga di beberapa Kabupaten Kota, kaum birokrat sedikit demi sedikit mulai tergeser dari kursi kepemimpinan eksekutif.
\end{abstract}

Abstract : This paper analyzed the application of political marketing communication by Local Elites in some of the momentum of Local Leader Elections in West Nusa Tenggara. The existence of local elites in NTB, which used to only be a getter vote, has now become a political figure who is ready to compete with politicians in seizing formal leadership at the local level. The ability of local elites to narrate their political vision and mission cannot be underestimated by pure politicians who have so far mastered the structure of political parties. Openness of Democracy must be used as a medium and momentum to seat all elements of the voting community who have the same rights, both can be proposed and elected as bureaucratic leaders. The political path is one of the pathways that allow local elites to sit in to fill leadership changes at the executive and legislative levels. NTB Province, as one of the regions that carried out Local Leader elections for several periods of leadership has now been led by local elites from religious figures, as well as in several districts, the Bureaucrats have gradually moved away from the executive leadership chair

\section{Pendahuluan}

Tulisan ini berangkat dari fenomena bangkitnya semangat politik elit-elit lokal dihampir seluruh daerah di Indonesia, termasuk di Provinsi Nusa Tenggara Barat (NTB). Elit-elit lokal yang tersebar di sepuluh kabupaten/kota se-NTB, kini telah menjelma sebagai aktor politik 
berpengaruh.Tingkat penetrasi dari pengaruh yang dimiliki elit-elit lokal terlihat dari keberhasilan mereka dalam memenangkan kontetasi elektoral dalam pemilihan umum kepala daerah (pilkada).

Pemilihan umum kepala daerah adalah salah satu amanat undang-undang yang harus direalisasikan oleh pemerintah pusat, dalam menjalankan roda regenerasi kepemimpinan di tingkat lokal. Apabila merujuk pada pasal 18 ayat (4) UUD NRI tahun 1945 yang menyebutkan bahwa 'Gubernur, Bupati, dan Wali Kota masing-masing sebagai kepala pemerintahan provinsi, kabupaten dan kota dipilih secara demokratis. ${ }^{1}$

Khusus di Provinsi NTB, publikdapat melihat bagaimana hasil dari proses demokrasi tersebut, dimana elit-elit lokal yang tersebar di beberapa ormas Islam berhasil memenangkan pertarungan konstestasi demokrasi tersebut. Salah satu contohnya adalah keberhasilan Dr. TGKH. M. Zainul Majdi, MA. Menjadi Gubernur NTB dua priode, Dr. KH. Zulkifli Muhadli, MM. Bupati Sumbawa Barat dua priode, TGH. Akhyar Abduh Wali Kota Mataram dua periode, Dr. TGH. Najmul Akhyar, MH. Memimpin Lombok Utara dua periode, TGH.Suhaili FT bupati Lombok Tengah dua periode. Mereka semua adalah elit lokal yang berkiprah di ranah keagamaan, namun kini mereka yang telah menjelma menjadi elit politik berpengaruh di daerahnya masing-masing.

Elite lokal yang dimaksud dalam tulisan ini adalah seseorang yang menduduki jabatan-jabatan strategis dan mempunyai pengaruh untuk memerintah orang lain dalam lingkungan masyarakat. Elit seperti ini sering disebut dengan elite non politik. Elit non politik ini seperti, elite keagamaan, elite organisasi kemasyarakatan, kepemudaan, profesi dan lain sebagainya Nurhasim dalam Rudi Subiakto. $^{2}$

Elit sering diartikan sebagai sekumpulan orang sebagai individu-individu superior, yang berbeda dengan massa yang menguasai jaringan-jaringan kekuasaan atau kelompok yang berbeda di lingkaran kekuasaan maupun yang sedang berkuasa. Mosca dan Pareto membagi stratifikasi elit ke dalam tiga kategori, yaitu elit yang memerintah (governing elit), elit yang tidak memerintah (non-governing elite) dan massa umum (non-elite). Melihat fakta keterlibatan elit dalam pemilihan umum kepala daerah, maka tepatlah pendapat Varma yang menyebutkan bahwa di dalam kelompok penguasa (the ruling class) selain ada elit yang berkuasa (the rulling elite) juga ada elit tandingan, yang mampu meraih kekuasaan melalui massa jika elit yang berkuasa kehilangan kemampuannya untuk memerintah. Artinya dalam hal ini, massa memegang sejenis kontrol jarak jauh atas elit yang berkuasa, tetapi karena mereka tak begitu acuh dengan dengan permainan kekuasaan, maka tak bisa diharapkan mereka akan menggunakan pengaruhnya. ${ }^{3}$

Keterlibatan elit lokal dalam pemilihan kepala daerah (Pilkada) bila dilihat dari orientasi politiknya dapat dibagi menjadi dua, yaitu pragmatis dan ideologis Pertama, Pragmatis adalah dimana tuan guru memosisikan dirinya sebagai "elit lokal" yang mempunyai kekuatan untuk memenangkan hajatan lima tahunan ini. Dengan demikian, Ia berhak mendapatkan hadiah atau imbalan setimpal dari apa yang telah dikerjakannya. Kedua, ideologis adalah terjunnya elit-elit keagamaan ke gelanggang politik merupakan panggilan hati untuk mengawal proses demokratisasi agar tercipta masyarakat yang aman, tentram, adil dan makmur atau dengan bahasa agama, masuknya Kiai ke ranah politik sebagai bagian amar ma'ruf nahi munkar, dan orientasi inilah yang paling menonjol dalam setiap aktifitas Kiai dalam ranah politik. ${ }^{4}$

\footnotetext{
${ }^{1}$ Agustino, Leo. (2009), Pilkada dan Dinamika Politik Lokal, Pustaka Pelajar, Yogyakarta, hal 79

${ }^{2}$ Subiakto, Henry, (2009). Komunikasi Politik: Media Massa dan Kampanye Pemilihan, Yogyakarta, Kalasutra, hal 48

${ }^{3}$ Varma, SP. Teori Politik Modern. (2010). (terj) dari Modern Political Theory oleh Yohanes Kristiarto SL. Cet:ke-9, Raja Grafindo Persada, Jakarta, hal 200

${ }^{4}$ Op.cit, hal 45
} 
Fenomena keterlibatan elit politik lokal dalam kompetisi di setiap momentum pemilihan umum adalah salah satu bentuk ekspresi demokrasi. ${ }^{5}$ Adapun Zuhro menyebutkan bahwa dalam konteks demokrasi dan budaya politik lokal, aktor adalah agency budaya.

Sebagai agency budaya, maka aktor sekaligus sebagai produsen (creator) budaya, dimana perilaku politik aktor di tingkat lokal mempengaruhi perubahan dan kesinambungan nilai-nilai budaya politik. Dengan kata lain, peran aktor merupakan salah satu kunci penting keberhasilan demokrasi karena tingkah laku aktor dan kebijakan yang dihasilkannya mempunyai arti penting dan juga berpengaruh signifikan terhadap konsolidasi demokrasi. ${ }^{6}$

Permasalahannya kemudian adalah terletak pada bagaimana strategi elit lokal tersebut dalam mengkomunikasi dan memasarkan visi-misi politknya di setiap perhelatan Pilkada. Disinilah berlakunya strategi (pendekatan) komunikasi politik dan Political Marketing untuk meyakinkan masyarakat pemilih yang terdiri dari berbagai segment tersebut. Tulisan ini menganalisa model komunikasi pemasaran politik (political marketing) elit lokal dalam pilkada, dengan fokus penelitian pada strategi political marketing elit lokal dalam memenangkan pemilihan kepala daerah di NTB.

\section{Kerangka Teoritik}

\section{A. Pemasaran Politik}

Istilah pemasaran politik (Political Marketing) dapat diartikan sebagai penerapan konsep pemasaran dalam politik, artinya pemasaran di dalam dunia politik praktis tidak jauh berbeda dengan penerapan konsep pemasaran dalam dunia bisnis komersial, dimana keduanya sama-sama memiliki standar dan strategi yang sama. Political marketing dalam pandangan Newman \& Perloff sebagaimana dikutif oleh Kaid menjelaskan pengertian pemasaran politik sebagai berikut.

'Pemasaran Politik adalah penerapan prinsip-prinsip dan prosedur dalam kampanye politik oleh beragam individu dan organisasi. Adapun prosedur-nya adalah analisis, pengembangan, pelaksanaan, dan pengelolaan kampanye strategis oleh kandidat, partai politik, pemerintah, pelobi dan kelompok-kelompok kepentingan yang berusaha untuk mendorong opini publik, memajukan ideologi mereka sendiri, memenangkan pemilu, dan meloloskan peraturan dan referendum dalam menanggapi kebutuhan dan keinginan dari orang-orang dan kelompok-kelompok yang dipilih dalam suatu masyarakat', ?

Pemasaran politik adalah sebuah konsep baru yang begitu lama dikenal dalam kegiatan politik, ia merupakan konsep yang diintroduksi dari penyebaran ide-ide sosial di bidang pembangunan dengan meniru cara-cara pemasaran komersial, tetapi orientasinya lebih banyak pada tatanan penyadaran, sikap dan perubahan perilaku untuk menerima hal-hal baru. Cara penyebaran seperti ini dilihat dari konteks dan orientasinya disebut "pemasaran sosial" yang secara subtantif tidak jauh berbeda dengan istilah penyuluhan, sosialisasi, dan kampanye. ${ }^{8}$

Adapun dalam kajian ilmu politik, political marketing merupakan penerapan ilmu marketing dalam kehidupan politik. Dalam political marketing, yang ditekankan adalah penggunaan pendekatan dan metode marketing dalam menyusun produk politik, distribusi produk politik kepada publik serta meyakinkan bahwa produk politiknya lebih unggul dibandingkan dengan pesaing, sehingga membantu politikus dan partai politik untuk membangun hubungan dua arah dengan konstituen dan masyarakat. ${ }^{9}$

\footnotetext{
${ }^{5}$ Nurpati, Andi. (2013). Dilema Eksistensi Pendidikan Politik Studi Atas Partisipasi Pemilih Dalam Pemilu, Yarsif Watampone, Jakarta., hal 1

${ }_{7}^{6}$ Zuhro, R. Siti dkk. 2009. Demokrasi Lokal Peran Aktor Dalam Demokratisasi, Ombak, Yogyakarta., hal 2

7 Kaid, Lynda Lee (Editor). (2004). Handbook Of Political Communication Research, London, Lawrence Erlbaum Associates Publishers, hal 18

${ }^{8}$ Cangara, Hafied. (2009). Komunikasi Politik, PT. Raja Grafindo Persada, Jakarta, hal 276

${ }^{9}$ Mage, Ruslan Ismail. (2012). Berpolitik Dengan Berbiaya Murah, Thafa Media, Yogyakarta., hal 141
} 
Dalam proses pemasaran politik, produk yang bisa dipasarkan adalah partai politik itu sendiri, tanda gambar, ideologi, visi-misi, program dan para kandidat yang akan menduduki jabatanjabatan politik. Semuanya itu memberikan citra, simbol dan kredibelitas sebuah produk politik (political product). ${ }^{10}$

\section{B. Strategi Pendekatan Pasar Politik}

Menurut Nursal apabila kandidat ingin memenangkan pertarungan dalam pemilihan, ada tiga strategi political marketing (pemasaran politik) yang dapat dilakukan dalam proses memasarkan agenda politiknya Pertama, Push Political Marketing (pemasaran politik langsung kepada calon pemilih). Kedua, Pull Political Marketing (Pemasaran politik melalui media massa). Ketiga Pass Political Marketing (Pemasaran politik melalui tokoh, kelompok atau organisasi berpengaruh). ${ }^{11}$

Push Political Marketing (Pemasaran politik langsung kepada calon pemilih), Menurut Nursal push-marketing adalah penyampaian produk politik langsung kepada para pemilih. Dalam pendekatan ini kandidat kepala daerah berusaha mendapatkan dukungan melalui stimulasi yang diberikan kepada pemilih. Masyarakat perlu mendapatkan dorongan dan energi untuk pergi ke bilik suara dan mencoblos seorang kontestan. Disamping itu kandidat perlu menyediakan sejumlah alasan yang rasional maupun emosional kepada para pemilih untuk bisa memotivasi mereka agar tergerak dan bersedia memberikan dukungan. Tanpa alasan-alasan ini, pemilih akan merasa ogah-ogahan karena mereka tidak punya cukup alasan untuk menyuarakan aspirasi mereka. Namun pada dasarnya push marketing adalah usaha agar produk politik dapat menyentuh para pemilih secara langsung dengan cara yang lebih mediaonal. ${ }^{12}$

Pull Political Marketing (Pemasaran politik melalui media massa) Menurut Nursal, pullmarketing adalah penyampaian produk politik dengan memanfaatkan media massa. Strategi seperti ini menitikberatkan pada pembentukan image politik yang positif. Roboniwitz dan Machdonald, menganjurkan bahwa supaya simbol dan image politik dapat memiliki dampak yang signifikan, kedua hal tersebut harus mampu membangkitkan sentimen. Pemilih cenderung memilih partai atau kandidat yang memiliki arah yang sama dengan apa yang mereka rasakan.

Pass Political Marketing (Pemasaran politik melalui tokoh, kelompok atau organisasi berpengaruh). Strategi ini menggunakan individu-individu, kelompok, dan organisasi berpengaruh yang dapat mempengaruhi opini pemilih (influencer). Sukses atau tidak penggalangan massa akan sangat ditentukan oleh pemilihan para influencer ini. Semakin tepat influencer yang terpilih, efek yang diraih pun akan menjadi semakin besar dalam mempengaruhi pendapat, keyakinan dan pikiran publik. ${ }^{13}$

\section{Penyajian dan Analisis Data}

Pemilihan kepala daerah di Provinsi Nusa Tenggara Barat menarik untuk dikaji dari berbagai aspek, apalagi dari sudut pandang komunikasi politik dan komunikasi pemasaran politik. Sebagaimana di singgung pada pendahuluan tulisan ini, kontestasi electoral di NTB ini sangatlah unik, dimana pesertanya adalah elit-elit lokal yang memiliki pengaruh kuat di masyarakat. Elit lokal yang tersebar di beberapa komunitas dan organisasi keagamaan ini saling berkompetisi meraih simpati dan empati Ummat untuk memilihnya.

\footnotetext{
${ }^{10}$ Arifin, Anwar. (2011). Komunikasi Politik Filsafat-paradigmatik-teori-tujuan-strategi dan komunikasi politik di Indonesia, Graha Ilmu, Yogyakarta, hal 147

${ }^{11}$ Firmanzah.(2008). Marketing Politik Antara Pemahaman dan Realitas, Jakarta Yayasan Obor Indonesia (YOI)., hal 218

${ }^{12}$ Nursal, Adman.(2004). Political Marketing Strategi Memenangkan Pemilu Sebuah Pendekatan Baru Kampanye Pemilihan DPR, DPD, Presiden, PT Gramedia, Jakarta, hal 242

${ }^{13}$ Op.cit, hal 244
} 
Dalam catatan penulis, setidaknya dalam beberapa pilkada di NTB yang pernah dijadikan ajang adu nyali para tuan guru dan kiai, Pemilihan Gubernur NTB 2008 (ada TGB M. Zainul Majdi), Pemilihan Gubernur NTB 2013 (TGB. M. Zainul Majdi, KH. Zulkifli Muhadli, TGH. L. Abdul Muhyi), Pemilihan Gubernur NTB 2018 (TGH, Akhyar Abduh, TGH, Suhaili FT, TGH. Gde Sakti, Lc., Ustadzah Dr. Hj. Rohmi Djalilah, M.Pd.).

Dari anatomi organisasi sosial keagamaan kandidat-kandidat gubernur NTB bermunculan, seperti Dr. M. M. Zainul Majdi, MA, selain sebagai gubernur incumbent juga masih duduk sebagai Ro is Am Dewan Tanfidziyah PBNW Pancor. Muhyi Abidin adalah sekjen PBNW Anjani (keluarga dari M. Zainul Majdi), Rohmi Djalilah (muslimat NW), KH. Zulkifli Muhadli (Pendekar Tapak Suci Putra Muhammadiyah), TGH. Suhaili, FT. (NU), TGH. Gde Sakti, TGH, Akhyar Abdu (NW).

Selain elit ormas keagamaan ada juga muncul elit-elit lokal yang muncul dari perwakilan setiap suku yang berasal dari Sasambo (Sasak, Samawa, Mbojo) pada Pemilihan Gubernur NTB 2013 ada kombinasi suku Mbojo-Sasak (Drs. H. Harun Al-Rasyid, M.Si - HL. Muhyi Abidin, MA.), Samawa-Sasak (Dr. KH.Zulkifli Muhadli, SH, MM - Prof. Dr. Ir. Ichsan, MS.), SasakSamawa (diwakili dua kandidat yakni Dr. KH. M. Zainul Majdi, MA. - H. Muhammad Amin, SH. M.Si. dan Suryadi Jaya Purnama, ST - Johan Rosihan, ST). Pada Pemilihan Gubernur 2018 juga formasinya masih mirip, dimana kombinasi sukuisme dan simbol ormas keagamaan dimunculkan

Dengan melihat banyaknya elit-elit lokal yang berkompetisi memperebutkan kursi NTB 1 dan 2 dalam setiap pemilihan kepala daerah di NTB.Penulis melihat semua kandidat menggunakan konsep komunikasi pemasaran politik dalam mengkomunikasi visi-misi politiknya untuk meyakinkan pemilih.

Semua kandidat berusaha menanamkan image dan citra diri dipromosikan (dipresentasikan) kepada khalayak.Kegiatan promosi diri itulah yang penulis simpulkan sebagai bagian dari strategi political marketing- setiap elit lokal yang berkompetisi dalam pemilihan kepala daerah di NTB.

Political marketing menurut Butler sebagaimana dikutif oleh Firmanzah adalah sebuah konsep permanen yang harus dilakukan terus-menerus oleh kontestan dalam membangun kepercayaan dan image publik. Sedangkan Dean dan Croft (2000) membangun kepercayaan dan image ini hanya bisa dilakukan melalui hubungan jangka panjang, tidak hanya pada masa kampanye.

Untuk menjadi seorang pemimpin (Gubernur, Bupati, Wali Kota) sangat mirip dengan berinvestasi dalam pasar saham. Jika anda mengharapkan kaya dalam sehari, anda takkan berhasil. Untuk sukses dalam industri politik, seorang aktor politik harus mampu memahami dengan benar karakteristik pasar demokrasi yang dilakoninya. Dalam konteks pasar demokrasi Indonesia, setidaknya ada empat karakteristik pasar demokrasi pasca reformasi. Pertama, pasar demokrasi yang menganut paham klasik 'suara rakyat suara Tuhan'. Kedua, pasar demokrasi selalu mengikuti perkembangan budaya setempat (kebiasaan pemilih) meliputi tingkat emosi, etika dan komunikasi yang baik dalam kehidupan sosial kemasyarakatannya. Ketiga, terjadinya pencerdasan pemilih secara alami, dari pemilih pragmatis menjadi pemilih kalkulatif. Keempat, pasar demokrasi selalu menuntut setumpuk modal untuk berinvestasi dalam pasar demokrasi. Para politisi Indonesia pada umumnya mengakui keempat karakter pasar demokrasi tersebut sebagai penentu kemenangan. ${ }^{14}$

Kondisi industri politik dalam pasar demokrasi yang cenderung berpihak kepada individu atau kelompok yang memiliki modal besar, bukan berarti menutup peluang individu atau kelompok lain yang kurang memiliki modal untuk menjadi pemenang. Fakta dari beberapa hasil pemilihan kepala daerah (pilkada) menunjukkan, ada juga kandidat yang tidak mengeluarkan banyak modal bisa menjadi pemenang.

\footnotetext{
${ }^{14}$ Mage, Ruslan Ismail. (2012). Berpolitik Dengan Berbiaya Murah, Thafa Media, Yogyakarta, hal 16
} 
Pada ranah ini, dibutuhkan kecerdasan intelektual seorang calon pemimpin untuk memahami strategi, karena kalau tidak memahami kiat-kiat sukses berinvestasi dalam industri politik, maka berapapun modal yang disiapkan tidak akan pernah cukup, di industri politik dibutuhkan investasi politik jangka pendek dan jangka panjang.

Investasi politik itu erat kaitannya dengan sebuah proses panjang yang dilakukan untuk mencari dan menyebar pengaruh di tengah masyarakat dalam rangka mendapatkan dukungan publik di bursa demokrasi (pemilihan). ${ }^{15}$

Dalam mendekati pasar politik jelang pemilihan kepala daerah, tentu dibutuhkan sebuah strategi atau pendekatan untuk mendapat perhatian dan minat pemilih untuk membeli produk politik setiap kandidat. Elit-elit lokal yang berkomeptisi dalam pemilihan umum kepala daerah di NTB berupaya untuk meraih dukungan masyarakat pemilih dengan menggunakan beberapa strategi pemasaran politik. Setelah terbentuknya visi-misi politik, kemudian dijabarkan ke dalam program-program kerja atau kebijakan yang akan mengangkat harkat dan martabat masyarakat NTB.

Visi-misi dan program kerja setiap kontestan tersebut dipresentasikan sendiri secara langsung kepada masyarakat pemilih dan melalui tim pemenangannya, dengan cara turun langsung ke masyarakat, melalui media massa, dan melalui dukungan elit-elit organisasi sosial kemasyarakatan seperti dukungan dari elit Nahdlatul Wathan (NW), elit NU, dan elit Muhammadiyah NTB.

Lalu seperti apa penerapan political marketing oleh elit-elit lokal dalam pemilihan kepala daerah di NTB, bagaimana penerapannya di lapangan? Berikut adalah deskripsi penerapan political marketing yang ditempuh oleh beberapa elit lokal yang berlaga dalam beberapa kali momentum pemilihan umum kepala daerah di NTB.

\section{A. Penerapan strategi push political Marketing}

Sebagaimana yang sudah dijelaskan pada bagian sebelumnya push political marketing adalah usaha seorang kandidat mendapatkan dukungan melalui stimulant yang diberikan kepada pemilih secara langsung. Strategi ini menurut Nursal dalam Firmanzah ${ }^{16}$ melihat bahwa masyarakat pemilih perlu mendapatkan dorongan dan energi untuk pergi ke bilik suara dan mencoblos kontestan.

Selain itu, kandidat atau partai politik perlu menyediakan alasan yang rasional maupun emosional kepada masyarakat pemilih untuk bisa memotivasi mereka agar tergerak dan bersedia mendukung kandidat yang diusungnya. Menurut Firmanzah, tanpa alasan-alasan ini, pemilih akan merasa ogah-ogahan karena tidak punya cukup alasan untuk menyuarakan aspirasi mereka.

Strategi ini, identik dengan aktivitas pemasaran politik yang digunakan oleh kandidat langsung kepada calon pemilih. Strategi ini digunakan oleh kandidat atau partai politik untuk mendapatkan dukungan melalui stimulan yang diberikan secara langsung kepada pemilih. Dalam hal ini, objek penelitian ini langsung bertatap muka dengan pemilih dan melakukan dialog dengan pemilih, mengkomunikasikan (baca, menawarkan) produk-produk politiknya.

Pada momentum Pemilihan Gubernur di NTB, setiap kandidat turun langsung ke masyarakat, salah satu contohnya adalah TGB.M. Zainul Majdi pada saat masa-masa kampanye selalu turun ke masyarakat memberikan pengajian-pengajian, pengajian itu bukan hanya di komunitas NW, tapi juga di tempat-tempat masjlis taklim yang dikelola oleh NU dan Muhammadiyah. Kegiatan tersebut dapat dikatakan sebagai strategi untuk mendapatkan dukungan dari masyarakat NU dan Muhammadiyah.

\footnotetext{
${ }^{15}$ Mage, Ruslan Ismail. (2012). Berpolitik Dengan Berbiaya Murah, Thafa Media, Yogyakarta., hal 17

${ }^{16}$ Firmanzah.(2008). Marketing Politik Antara Pemahaman dan Realitas, Jakarta Yayasan Obor Indonesia (YOI), hal 217
} 
Itulah investasi politik jangka panjang yang ditanamkan M. Zainul Majdi, sehingga langkahnya tersebut tidak mengagetkan pasar demokrasi NTB, karakter ketokohannya tidak dimunculkan secara tiba-tiba, tetapi benar-benar ia rawat jauh sebelum dan selama menjadi gubernur NTB. Momen-momen kandidat turun langsung ke masyarakat memiliki kesamaan, akan tetapi karena status elitnya berbeda maka bentuk-bentuk kegiatan pertemuan langsung dengan masyarakat pemilih berbeda beda.

\section{B. Penerapan strategi Pull Political Marketing}

Strategi ini diidentikkan dengan penggunaan media massa (cetak, elektronik, dan online). Artinya proses pemasaran produk politik melalui media massa. Media massa memiliki kemampuan dalam menggiring partisipasi politik warga, Nursal misalnya menempatkan media sebagai salah satu wadah pendulang suara dalam setiap kegiatan pemilihan.

Adapun Effendy ${ }^{17}$ menyebutkan bahwa saking berkuasanya media massa dalam mempengaruhi pikiran, perasaan, dan prilaku penduduk. Effendy meminjam pendapat Kevin Philips yang menyebut era sekarang lebih merupakan mediacracy (pemerintahan media), Daripada democracy (pemerintahan rakyat).Pendapat efendy tersebut ada benarnya, apalagi kalau dikaitkan dengan preperensi pilihan politik masyarakat pemilih. Media massa dijadikan sebagai rujukannya.

Penulis menemukan bahwa semua elit-elit lokal yang berkompetisi di beberapa momen pilkada NTB, seperti KH. Zulkifli Muhadli, TGH, Lalu Abdul Muhyi, TGH, Akhyar Abduh dan TGB. M. Zainul Majdi, secara massif menggunakan media massa untuk memperkenalkan diri, baik melalui udara (Radio, Televisi Lokal), maya (internet seperti Facebook, Twiter, Youtube) dan darat (Koran, Baliho, striker, spanduk, kalender).

Dalam kompetisi elektoral di tingkat lokal, penerapan strategi ini tidak memiliki perbadaan antara satu kandidat dengan kandidat yang lainnya, misalnya dalam penggunaan media cetak dan elektronik, semua kandidat yang bertarung, sama-sama menggunakan media untuk mensosialisasikan diri dan visi-misinya. Perbedaan dapat kita temukan hanya pada besar-kecilnya anggaran dana kampanye lewat media massa, hal ini turut mempengaruhi volume pemuatan pesan-pesan politik antar kandidat di media massa.

\section{Penerapan strategi Pass Political Marketing}

Strategi Pass political marketing, pemasaran produk politik melalui orang atau kelompok berpengaruh yang mampu mempengaruhi opini pemilih. Kelebihan dari proses ini adalah dengan melakukan pass political marketing dapat menekan biaya karena sudah memegang kepala kelompok pemilih, memudahkan koordinasi antara kandidat dengan opinion leader-nya, dan dapat dijadikan sebagai sumber penggalangan isu-isu di daerah pemilihan. Kelemahan dari pass political marketing adalah pada peneguhan dukungan jika tidak dikontrol dapat lepas, tidak semua kelompok terdapat opinion leadernya dan sikap, dan kedewasaan dan kesadaran politik sudah mulai tumbuh di masyarakat sehingga pemilih dapat mengunduh dan memilah informasi yang berguna ataupun sebaliknya dari setiap visi misi dan janji-janji dari setiap kandidat.

Elit lokal yang berkompetisi dalam pemilihan umum kepala daerah di NTB, banyak menggunakan kelompok, komunitas, ormas untuk mendapatkan dukungan politik dari pemilih. Misalnya HM. Ali BD yang bertarung pada Pemilihan Gubernur NTB 2018 secara massif menampilkan komentar dan testimoni dari tokoh-tokoh agama, adat dan ormas untuk diterbitkan di media cetak setiap hari.

\footnotetext{
${ }^{17}$ Firmanzah.(2008). Marketing Politik Antara Pemahaman dan Realitas, Jakarta Yayasan Obor Indonesia (YOI), hal 162
} 
HM. Ali Bin Dahlan, misalnya mempublikasikan komentar, pesan-pesan dan testimoni para tokoh dari kalangan tuan guru, pimpinan pesantren, tokoh adat dan budaya atas kiprah HM Ali Bin Dahlan selama menjadi Bupati, hal yang sama juga dilakukan oleh HM. Zainul Majdi, kedua kandidat yang pernah berkompetisi dalam pemilihan umum kepala daerah di NTB tersebut samasama menggunakan tokoh ormas dan masyarakat untuk menggaet hati pemilih, demikian juga dengan elit-elit lokal lainnya yang berkompetisi merebut kursi gubernur, bupati, wali kota, masih sering menggunakan jasa tokoh-tokoh masyarakat untuk menjadi pengepul suara.

Adapun, dukungan dari elit NU, NW, Muhammadiyah sangat diburu oleh semua kandidat agar mendapat simpati masyarakat pemilih, penulis mendapatkan bahwa elit-elit lokal seperti $\mathrm{M}$. Zainul Majdi memanfaatkan kedekatan dirinya di berbagai macam momen atau kesempatan untuk bertemu langsung dengan jamaah NW, NU, Muhammadiyah, melalui pengajian-pengajian umum yang banyak melibatkan jamaah dan anggota ormas Islam tersebut di akar rumput. Dukungan para elit-elit lokal yang ada di ormas NU, Muhammadiyah dan sebagainya itu sebenarnya adalah muara dari hubungan relasional antar sesama elit lokal (tuan guru), hubungan relasional itu sudah terbangun jauh sebelum mereka terjun ke dunia politik praktis.

Intensitas pertemuan-pertemuan informal dalam momen pengajian-pengajian ini biasa dilakukan pada hari-hari libur kerja, seperti hari sabtu, dan pada momen-momen hari jum'at dengan menjadi khotib dan imam sholat jum'at, sedangkan terkait dengan pertemuan-pertemuan bersama organisasi keagamaan, para kandidat biasa mendatangi komunitas-komunitas ormas tersebut.

\section{Kesimpulan}

Pendekatan political marketing digunakan oleh semua elit lokal yang berkompetisi dalam meraih simpati dan empati pemilih dalam pemilihan umum kepala daerah di NTB. Hasil akhirnya kemudian adalah siapa yang paling massif menggunakan dan menerapkan semua strategi terssebut behrasil keluar sebagai pemenangnya. Salah satunya adalah TGB. M. Zainul Majdi berhasil memimpin NTB dua periode, kemudian Dr. KH. Zulkifli Muhadli berhasil memimpin Sumbawa Barat selama dua periode, TGH Akhyar Abduh Berhasil memimpin Mataram selama dua periode, Suhaili FT berhasil melanggengkan kepemimpinannya selama dua periode di Lombok tengah. Hal yang sama dilakukan oleh TGH. Najmul Akhyar Bupati Lombok Utara.

Adapun kesimpulan yang terkait dengan penerapan Political Marketing oleh elit lokal dalam pilkada di NTB, dapat disimpulkan sebagai berikut: Strategi Push Political Marketing elit lokal yang berkompetisi dalam pilkada NTB langsung turun ke masyarakat, dengan melakukan kegiatan-kegiatan sosial keagamaan, seperti pengajian, sholat jum`at keliling. Kemudian penerapan Full Political Marketing, hampir semua kandidat melakukan presentasi (promosi) politik melalui media massa, dan terakhir adalah penerapan Pass Political Marketing, strategi ini lebih ditekankan pada promosi politik melalui orang-orang berpengaruh di masyarakat, atau melalui organisasi sosial kemasyarakatan.

Peluang elit lokal yang berasal dari unsur-unsur keagamaan akan terus mendapatkan kursi kepemimpinan di ranah lokal, bergantung pada bagaimana mereka menggunakan dan menerapkan strategi komunikasi pemasaran politik, secara massif, terukur dan terkordinir dengan baik. 


\section{DAFTAR PUSTAKA}

Agustino, Leo. (2009), Pilkada dan Dinamika Politik Lokal, Pustaka Pelajar, Yogyakarta.

Arifin, Anwar. (2011). Komunikasi Politik Filsafat-paradigmatik-teori-tujuan-strategi dan komunikasi politik di Indonesia, Graha Ilmu, Yogyakarta.

Cangara, Hafied. (2009). Komunikasi Politik, PT. Raja Grafindo Persada, Jakarta.

Firmanzah.(2008). Marketing Politik Antara Pemahaman dan Realitas, Jakarta Yayasan Obor Indonesia (YOI).

Kaid, Lynda Lee (Editor). (2004). Handbook Of Political Communication Research, London, Lawrence Erlbaum Associates Publishers.

Mage, Ruslan Ismail. (2012). Berpolitik Dengan Berbiaya Murah, Thafa Media, Yogyakarta.

Nursal, Adman.(2004). Political Marketing Strategi Memenangkan Pemilu Sebuah Pendekatan Baru Kampanye Pemilihan DPR, DPD, Presiden, PT Gramedia, Jakarta.

Nurpati, Andi. (2013). Dilema Eksistensi Pendidikan Politik Studi Atas Partisipasi Pemilih Dalam Pemilu, Yarsif Watampone, Jakarta.

Sayuti, Solatun Dulah. (2014). Komunikasi pemasaran politik, Rosdakarya, Bandung.

Subiakto, Henry, (2009). Komunikasi Politik: Media Massa dan Kampanye Pemilihan, Yogyakarta, Kalasutra.

Varma, SP. Teori Politik Modern. (2010). (terj) dari Modern Political Theory oleh Yohanes Kristiarto SL. Cet:ke-9, Raja Grafindo Persada, Jakarta

Zuhro, R. Siti dkk. 2009. Demokrasi Lokal Peran Aktor Dalam Demokratisasi, Ombak, Yogyakarta.

Center, Jakarta.

(2011). Model Demokrasi Lokal Jatim, Sumbar, Sulses dan Bali, The Habibie

\section{JURNAL}

Andrew Lock and Phil Harris, Political marketing - Vive la différence! European Journal of Marketing 30,10/11 1996, pp. 14-24. (C MCB University Press, 0309-0566.

Haryanto, Elit Politik Lokal dalam Perubahan Sistem Politik, dalam Jurnal Ilmu Sosial dan Ilmu Politik Volume 13, Nomor 2, November 2009 (131-148) ISSN 1410-4946 Universitas Gajah Mada Yogyakarta.

Rudi Subiakto, Keterlibatan Kiai dalam Pilkada, studi pilkada Banjarnegara 2006, dalam Jurnal Ilmu Politik dan Ilmu Pemerintahan, Vol. 1, No. 1, 2011 Univeritas Maritim Ali. 